\title{
MODEL JARINGAN KOMUNIKASI DALAM MENGOLAH LAHAN TANPA BAKAR OLEH MASYARAKAT DI KOTA DUMAI
}

\author{
Jeki Rahman ${ }^{1}$, Rosnita ${ }^{2}$ \\ ${ }^{1}$ Program Studi Agribisnis Fakultas Pertanian Universitas Riau \\ email: ${ }^{1}$ jq.rahman11@gmail.com, ${ }^{2}$ rosnitamag@gmail.com
}

\begin{abstract}
ABSTRAK
Penelitian ini bertujuan untuk (1) mengetahui metode pengolahan lahan tanpa bakar yang dilakukan oleh masyarakat di Kota Dumai ,(2) mengetahui struktur jaringan komunikasi yang terbentuk antar individu dalam mengolah lahan tanpa bakar.Metode pengambilan sampel yang digunakan pada penelitian ini adalah menggunakan teknik snowball sampling. Hasil penelitian menunjukkan bahwa masyarakat di Kota Dumai tidak lagi melakukan pengolahan lahan dengan cara bakar melainkan sudah beralih dengan menggunakan metode dengan tanpa bakar, karena pemerintah memberlakukan larangan pembakaran dalam proses mengolah lahan. Struktur jaringan komunikasi yang terbentuk dalam mengolah lahan tanpa bakar yaitu membentuk struktur roda yang memusat pada satu individu dalam jaringan komunikasi, di Kelurahan Bangsal Aceh informasi terpusat pada aktor Muhammad Rizal sedangkan di Kelurahan Tanjung palas terpusat pada aktor Yustanto dan Warino, Sebaiknya struktur jaringan komunikasi yang terbentuk yaitu struktur semua saluran (all Channel) agar setiap individu dalam jaringan dapat melakukan interaksi secara timbal balik tanpa menganut siapa yang menjadi tokoh sentral dalam memperoleh informasi.
\end{abstract}

Kata kunci : jaringan komunikasi, tanpa bakar

\section{ABSTRACT}

This research aims to (1) knowing the method of processing land zero burning that people in the city of Dumai., (2) to know the structure a network of communication between individuals in processing land zero burning. The method of sampling used in this study is an application of the snowball sampling technique. The results showed that people in the city of Dumai stopped processing by burning but turned to the method of processing land zero burning, as the government imposed a ban on burning in the cultivation of land.The structure of communication networks in processing land zero burning that of forming wheel structures that dissolve in one indvidual within the communication network, in Bangsal Aceh village centered on Muhammad Rizal actor, while in Tanjung Palas village centered on yustanto and warino actors, it is better if the network communication that formed is the structure of all channels so that each individual in the network can interact reciprocally without adhering to the theory of who is the central figure in obtaining information.

Keywords: communication networks, zero burning

\section{PENDAHULUAN}

Provinsi Riau merupakan salah satu wilayah yang rawan terhadap bencana, baik bencana alam maupun sosial. Bencana alam yang sering terjadi di Riau adalah kebakaran hutan dan lahan yang mengakibatkan timbulnya kerugian baik dari segi ekologi maupun sosial masyarakat. Penyebab dari kebakaran hutan dan 
lahan ada dua, yakni faktor alam dan faktor manusia. Faktor alam, seperti faktor musim, lahan gambut yang mudah terbakar serta kandungan mineral yang tidak dapat dihindari. Sedangkan faktor manusia yaitu disebabkan oleh aktivitas membuka atau mengolah lahan dengan cara bakar karena dianggap lebih mudah, murah dan cepat .

Kebakaran lahan di Kota dumai merupakan salah satu penyumbang terbesar hampir di setiap tahunnya. berdasarkan data BPBD Provinsi Riau pada tahun 2019, wilayah luas areal kebakaran lahan di Kota Dumai yaitu $266.75 \mathrm{Ha}$. Data BPBD Kota Dumai tahun 2018 mencatat bahwa Kecamatan Sungai Sembilan, dan Kecamatan Dumai Timur merupakan kecamatan di Kota Dumai yang memiliki luas wilayah terbakar dan frekuensi kebakaran yang lebih sering dalam satu tahun dibandingkan dengan kecamatan yang lainya. Sehingga dipilihlah Kecamatan Sungai Sembilan dan Kecamatan Dumai Timur sebagai lokasi penelitian.

Berbagai upaya dilakukan untuk mengurangi tingkat kebakaran lahan di Kota Dumai, diantaranya baik itu melalui sosialisasi, himbauan maupun pengawasan terkait dengan mengolah lahan dengan cara bakar. Pemerintah melalui undang-undang nomor 18 tahun 2004 pasal 26 telah melarang aktivitas membuka dan mengolah lahan dengan cara bakar. Salah satu alternatif melakukan pengolahan lahan yang ramah lingkungan yaitu dengan metode pengolahan lahan tanpa bakar yang mana dalam praktiknya tidak melakukan pembakaran terhadap sisa hasil tebangan. Hal ini senada dengan yang disampaikan Onrizal (2008) yang mengemukakan teknik yang ramah lingkungan pengganti teknik tebang bakar yaitu metode slash and mulch (lahan tanpa bakar), dimana dalam praktik nya tidak melakukan pembakaran melainkan dengan menebang atau menebas vegetasi disekitar areal lahan yang kemudian ditumpuk dan dibiarkan terdekomposisi secara alami dan berfungsi sebagai mulsa. Secara umum kegiatan mengolah lahan tanpa bakar dapat dikelompokkan kedalam kegiatan : persiapan, penebasan dan penebangan, pembersihan lahan lalu hasil tumbangan di biarkan secara alami hingga terdekomposer.

Minimnya akses informasi dan pengetahuan masyarakat terkait metode mengolah lahan tanpa bakar yang ramah lingkungan menjadi permasalahannya, yang mana permasalahan tersebut berakar pada arus informasi yang belum merata kepada setiap individu. Informasi yang minim mengakibatkan masyarakat hanya mengandalkan pengalaman turun temurun dalam aktivitas mengolah lahan Sebagai dampak positif dari inovasi mengolah lahan tanpa bakar ini terhadap lingkungan, maka informasi mengenai teknik mengolah lahan tanpa bakar sangat perlu untuk dikomunikasikan atau disebarluaskan ke tengah masyarakat. Sehingga Proses pertukaran informasi yang terjadi antar indvidu yang saling berhubungan akan menggambarkan adanya pola jaringan yang muncul sebagai akibat kebutuhan informasi. Individu -individu yang saling berinteraksi di dalam jaringan akan memiliki peranan khusus seperti pemuka pendapat (opinion leader), stars ,cosmopolite, jembatan (bridge), dan pencilan (isolated). Adapun yang tujuan penelitian yaitu (1) mengetahui metode mengolah lahan tanpa bakar yang dilakukan oleh masyarakat di Kota Dumai, (2) menganalisi struktur jaringan komunikasi yang terbentuk 
dalam mengolah lahan tanpa bakar di Kota Dumai.

\section{METODE PENELITIAN}

Penelitian ini dilaksanakan di Desa Bangsal Aceh dan Tanjung Palas yang terdapat di Kecamatan sungai Sembilan dan Kecamatan Dumai Timur Kota Dumai. Pemilihan lokasi penelitian dilakukan secara sengaja (purposive), dengan beberapa pertimbangan diantaranya yaitu : 1) desa yang dipilih sebagai tempat penelitian merupakan desa yang setiap tahunnya mengalami kebakaran lahan di Kota Dumai, 2) merupakan desa dengan luas areal kebakaran terluas di Kota Dumai. 3) merupakan desa dengan frekuensi kebakaran terbanyak di Kota Dumai, Serta 4) mempunyai lembaga Masyarakat Peduli Api (MPA).

Metode yang digunakan dalam penelitian ini adalah metode survey dan wawancara mendalam menggunakan kuisioner. Pengambilan sampel dilakukan dengan metode snowball sampling yaitu pengambilan sampel melalui proses bergulir dari satu responden ke responden lainnya dengan key informan awal yaitu ketua Masyarakat Peduli Api (MPA) di Kelurahan Bangsal Aceh dan Perangkat Desa di Kelurahan Tanjung Palas. Jenis data yang digunakan dalam penelitian ini yaitu data primer dan data sekunder yang bersifat kualitatif dan kuantitatif. Data primer yang dikumpulkan yakni data karakteristik internal petani terdiri dari: umur, tingkat pendidikan, lama pengalaman berusahatani, luas lahan, tingkat kekosmopolitan (Alfirahmawati, 2016).

Guna mendukung data primer di lapangan, dibutuhkan data sekunder yang didapat dari instansi terkait seperti Kantor Lurah Bangsal Aceh dan Kantor Lurah Tanjung Palas, data monografi Desa Bangsal Aceh dan Desa Tanjung
Palas, dan data skunder lainnya yang dibutuhkan untuk penelitian ini.

Untuk menjawab tujuan pertama dengan di analisis menggunakan deskriptif kualitatif dengan menggambarkan fenomena yang terjadi dilokasi penelitian terkait dengan metode mengolah lahan tanpa bakar. Untuk menjawab tujuan ke dua dianalisis dengan dengan uji sosiometri menggunakan aplikasi UCINET VI.

\section{III.HASIL DAN PEMBAHASAN}

\section{Metode Pengolahan Lahan tanpa bakar yang Biasa di Lakukan Masyarakat di Kota Dumai}

Adinugroho dalam Purwo (2016) menyatakan bahwa hampir 99,9\% kebakaran hutan dan lahan yang terjadi diakibatkan oleh aktivitas manusia baik yang di sengaja maupun tidak. Salah satunya adalah kegiatan bertani yang dilakukan masyarakat yang mana biasanya dalam melakukan proses pengolahan lahan masyarakat lebih cendurung memilih teknik pengolahan lahan dengan cara dibakar, dengan alasan bahwa mengolah lahan dengan cara dibakar lebih cepat dan efisien dari segi biaya.Salah satu upaya pemerintah dalam menanggulangi kebakaran lahan dan hutan adalah dengan mengeluarkan peraturan serta sanksi keras terkait larangan membakar lahan dan hutan baik itu untuk kegiatan pertanian maupun non pertanian seperti yang tercantum dalam Undang-undang No 18 tahun 2004 yang menyebutkan bahwa setiap pelaku usaha perkebunan di larang membuka atau mengolah lahan dengan cara pembakaran yang berakibat terjadinya pencemaran dan kerusakan fungsi lingkungan hidup, telah membuat pihak perkebunan mau tidak mau harus mempertimbangkan penyiapan lahan zero burning. 
Kota Dumai menjadi salah satu daerah di Riau dengan luas lahan yang terbakar paling luas, hal ini dibuktikan dengan data BPBD provinsi Riau tahun 2019 yang menunjukan Kota Dumai berada pada posisi ke 5. Kebakaran lahan yang terjadi di Kota Dumai tersebar di beberapa wialayah, yang mana daerah yang paling luas terbakar terdapat di Kelurahan Tanjung Palas Kecamatan Dumai Timur 74,5 Ha dan Kelurahan Bangsal Aceh Kecamatan Sungai Sembilan 67 ha. Kebakaran yang terjadi di Kota Dumai sebagian besar di sebabkan oleh aktivitas manusia baik dari masyarakat umum maupun perusahaan-perusahan yang bergerak pada bidang perkebunan maupun industri. Masyarakat di Kelurahan Tanjung Palas dan Kelurahan Bangsal Aceh sebagian besar bekerja pada sektor pertanian baik yang di tanaman perkebunan maupun tanaman hortikultura. Dalam melakukan pengolahan lahan masyarakat dulunya melakukan pengolahan lahan secara bakar yang mana teknik pengolahan lahan ini di anggap lebih cepat dan lebih efisien. Untuk lahan dengan skala luas lebih dari $1 \mathrm{Ha}$ masyarakat pada umumnya menggunakan alat berat (stacking) dalam proses penumbangan maupun penimbunan pada metode mengolah lahan tanpa bakar. Sedangkan untuk lahan dalam skala yang lebih kecil pada umumnya masyrakat melakukan pembabatan terlebih dahulu setelah 3 bulan kemudian dilakukan penyemprotan dengan mengguna kan "racun bakar" dengan maksud agar tanaman yang sudah dibabat mati dan tidak tumbuh lagi. Sebagian responden berpendapat bahwa karena kalau membakar bisa merusak tekstur tanah sehingga kurang baik untuk bercocok tanam.

\section{Analisis Jaringan Komunikasi dalam Mengolah Lahan tanpa Bakar di Kelurahan Bangsal Aceh dan Kelurahan Tanjung Palas Kota Dumai.}

Analisis jaringan komunikasi merupakan salah satu metode yang digunakan untuk mempelajari perilaku komunikasi antar indvidu yang saling berhubungan yang menghasilkan gambaran struktur atau pola arus komunikasi yang terjalin antara responden dalam bentuk sosiogram. Sosiogram jaringan komunikasi menggambarkan pola interaksi yang terbentuk antar individu dalam suatu sistem. Melalui sosiogram jaringan komunikasi dapat diidentifikasi struktur komunikasi yang terbentuk dan seberapa banyak individu yang dapat terhubung dengan individu lainnya. Lebih lanjut dapat diidentifiksai pula peran individu dalam jaringan. Sosiogram pada Gambar 1 menggambarkan komunikasi responden dalam mengolah lahan tanpa bakar di Desa Bangsal Aceh.

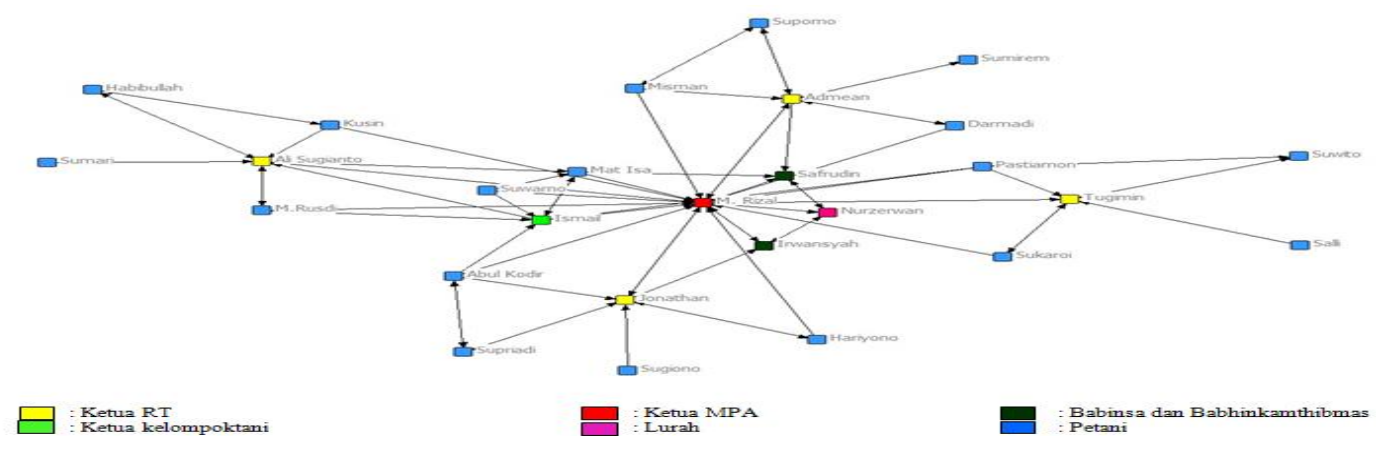


Gambar 1. Sosiogram Jaringan komunikasi mengolah lahan tanpa bakar di Kelurahan Bangsal Aceh dan Tanjung Palas

Berdasarkan Gambar 1, dapat
dilihat bahwa bentuk jaringan komunikasi yang memusat pada masyarakat di Kelurahan Bangsal Aceh menggambarkan adanya perananperanan khusus yang dimiliki oleh individu dalam jaringan. Pola yang terbentuk yaitu pola roda dengan pusat roda pada Bapak Muhammad Rizal yang berperan sebagai ketua Masyarakat Peduli Api (MPA) Bangsal Aceh.Bentuk jaringan komunikasi roda sebenarnya cukup baik karena dapat bergerak pada satu komando dimana ketika individu A menyarankan pada individu B, C dan D maka individu B, $\mathrm{C}$, dan $\mathrm{D}$ akan mengikuti perintah tersebut dan kepengawasan terpusat pada Bapak Muhammad Rizal sebagai pemimpin dalam sistem.

Adapun peranan individu pada jaringan komunikasi mengelola lahan tanpa bakar di Kelurahan Bangsal Aceh adalah sebagai berikut:

\section{Star}

Aktor yang dapat dikatakan sebagai star adalah orang yang intensitas dihubunginya banyak atau dikatakan aktor sentral. pada jaringan komunikasi mengelolah lahan tanpa bakar di Kelurahan Bangsal Aceh ini individu berperan sebagai star ditunjukkan oleh Bapak Muhammad Rizal. Individu ini merupakan orang paling populer di dalam jaringannya danaktif dalam berbagai organisasi di Kelurahan Bangsal Aceh. Organisasi yang sedang diikutinya antara lain ketua RT dan ketua masyarakat peduli api (MPA). Aktifnya Bapak Muhammad Rizal dalam berbagai organisasi setempat, menjadikan bapak ini banyak dikenal oleh masyarakat setempat.

\section{Bridge}

Bridge merupakan anggota suatu kelompok/sub kelompok yang berhubungan dengan kelompok lainnya dan menjadi jembatan informasi bagi anggota kelompoknya.Berdasarkan gambar 8 dapat diketahui bahwa Bapak Ali Sugianto, Bapak Tugimin, Bapak Admean dan Bapak Jonathan menjadi bridge dalam jaringan. Keempat individu ini menjadi bridge karena berhubungan dengan posisi dan peranan mereka di dalam pemerintahan Kelurahan Bangsal Aceh sebagai ketua RT. Keempat individu berperan besar sebagai bridgeatau jembatan bagi masyarakat untuk mendapatkan informasi mengolah lahan tanpa bakar dari Bapak Muhammad Rizal yang berstatus sebagai ketua masyarakat peduli api (MPA).

\section{Cosmopolite}

Cosmopolitemerupakan individu yang menghubungkan kelompok dengan pihak eksternal atau lingkungannya. individu ini mengumpulkan informasi dari sumbersumber yang ada dalam lingkungan dan memberi informasi mengenai mengolah lahan tanpa bakar kepada individu tertentu dalam jaringan. peran ini ditunjukkan oleh Bapak Muhammad Rizal, Bapak Ali Sugianto, Bapak Admean, dan Bapak Tugimin. Kelima individu ini memiliki otoritas formal di Kelurahan Bangsal Aceh.Individu ini merupakan individu yang menghubungkan masyarakat dengan pihak luar yaitu Lurah, Babinsa, dan Babhinkamtibmas dalam mendapatkan informasi mengolah lahan tanpa bakar. 


\section{Gate keeper}

Gate keeper merupakan orang melakukan filtering terhadap informasi yang masuk sebelum dikomunikasikan kepada anggota kelompok/sub kelompok tergantung dari penting atau tidak pentingnya informasi untuk organisasi.Menurut Scott (2009), individu dengan nilai kebersamaan tinggi mempunyai potensi kendali komunikasi yang dapat memainkan potensi sebagai gate keeper dalam suatu jaringan. Berdasarkan hasil output menggunakan UCINET VI, didapatlah peran gate keeper dengan nilai kebersamaan terbesar yaitu Bapak
Muhammad Rizal yang merupakan ketua masyarakat peduli api (MPA) yang cukup sering memberikan informasi pada masyarakat khususnya berkenaan dengan informasi mengolah lahan tanpa bakar.

Peran gate keeper yang ditunjukkan oleh Bapak Muhammad Rizal dikarenakan beliau dianggap sebagai petani yang paling berhasil dengan tingkat pendapatan yang tinggi serta kepemilikan lahan mencapai 10 ha. Luas lahan yang diusahakan oleh Pak Rizal terbilang sangat luas untuk ukuran petani di Kelurahan Bangsal Aceh menyebabkan beliau memiliki potensi kendali komunikasi.

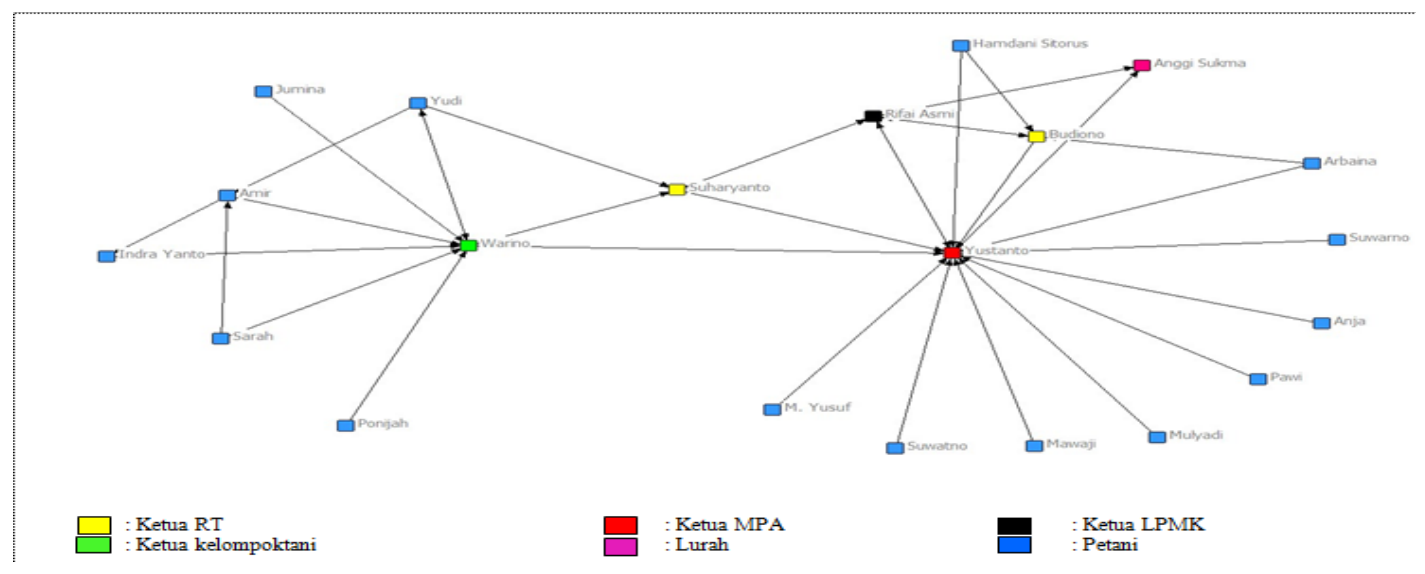

Gambar 2. Sosiogram Jaringan komunikasi mengolah lahan tanpa bakar di Kelurahan Bangsal Aceh dan Tanjung Palas

Gambar2 dapat menjelaskan bahwa pola jaringan yang terbentuk yaitu pola terpusat atau yang biasa disebut pola roda yang berpusat pada Bapak Yustanto dan Bapak Warino, yang mana masing individu ini memiliki jabatan di kelurahan tanjung palas yaitu sebagai ketua MPA (masyarakat peduli api) dan ketua kelompok tani.Adapun peranan tiap-tiap aktor dalam jaringan komunikasi mengolah lahan tanpa bakar di Kelurahan Tanjung Palas adalah sebagai berikut :

1. Star

Individu yang dapat dikatakan sebagai star adalah orang yang intensitasnya dihubunginya banyak atau dikatakan aktor sentral atau juga sering dikatakan sebagai aktor yang popular dalam sistemnya. Berdasarkan Gambar 2 dapat dilihat bahwa yang menjadi star pada jaringan komunikasi mengolah lahan tanpa bakar di Kelurahan Tanjung Palas adalah Bapak Yustanto. Individu 
ini merupakan merupakan ketua masyarakat peduli api (MPA) dan sudah terkenal dikalangan masyarakat. Bapak Yustanto menjadi star karena keaktifannya di MPA sehingga dengan jabatannya tersebut maka timbul minat masyarakat untuk bertanya dan merangsang masyarakat untuk lebih giat dalam berusaha tani dan membantu memperkaya informasi mengolah lahan tanpa bakar, hal ini senada dengan pendapat (Sulistiawati, 2014) yaitu Saluran komunikasi yang paling tepat untuk mengubah sikap atau perilaku petani adalah saluran interpersonal atau interpribadi yang contohnya seperti cara Bapak Yustanto dalam meberikan informasi kepada masyarakat.

\section{Bridge}

Individu yang berperan sebagai bridge dalam jaringan komunikasi mengolah lahan tanpa bakar di kelurahan tanjung palas yaitu di tunjukan oleh Bapak Warino. Posisinya sebagai ketua kelompoktani membuatnya sering berhubungan dengan sumber-sumber informasi seperti dengan Bapak Yustanto sebagai ketua MPA dan Bapak Suharyanto sebagai ketua RT, sehingga ia memiliki banyak informasi. posisinya di dalam kelompok atau diluar kelompok sangat memungkinkan baginya dapat mengakses sejumlah informasi dan juga memiliki kekuasaan untuk mengendalikan arus informasi dalam jaringan komunikasi di kelompoknya. selain sebagai bridge, ia juga dapat berperan sebagai opinion leader yaitu pimpinan informal dari dari suatu organisasi yang dapat mempengaruhi tingkah laku dan pengambilan keputusan dalam suatu sistem.

\section{Cosmopolite}

peran cosmopolite yaitu individu yang menghubungkan kelompok dengan pihak luar adalah Bapak Rifai Hasmi dan Bapak Yustanto. Kedua individu ini merupakan pemimpin formal dalam kelompoknya. Individu ini merupakan individu yang menghubungkan masyarakat dalam mendapatkan informasi dari Bapak LurahKelurahan Tanjung Palas. Bapak Rifai Hasmi adalah Ketua Lembaga Pemberdayan Masyarakat Kelurahan (LPMK). Selain itu,beliau merupakan tokoh masyarakat sekaligus tokoh agama yang aktif dalam sejumlah organisasi di Kelurahan Tanjung Palas.

\section{Gate keeper}

Gate keeper merupakan aktor yang mengontrol arus informasi di antara anggota organisasi dan umumnya berada ditengah suatu jaringan. Individu memainkan potensi sebagai gatekeeperadalah Bapak Yustanto dan Bapak Warino. Kedua Individu memiliki peranan penting dalam menyampaikan suatu informasi pada masyarakat lain yang menurutnya info itu penting untuk disampaikan.

\section{Jaringan komunikasi tingkat individu 1. Sentralitas lokal}

Sentralitas lokal menunjukkan jumlah hubungan yang dapat dibuat oleh individu dengan individu lainnya yang saling berhubungan dalam jaringan komunikasi.Menurut Scoot (2009)sentralitas lokal menunjukkan jumlah hubungan yang dapat dibuat individu dengan individu lain dalam sistem. Seorang yang memiliki sentralitas lokal tinggi umumnya adalah seorang yang aktif dalam jaringan komunikasi. 
Tabel 1. Nilai maksimum dan minimum sentralitas lokal di Kelurahan Bangsal Aceh

\begin{tabular}{|c|c|}
\hline Indeks Jaringan Komunikasi & Kelurahan Bangsal Aceh \\
\hline 1. Sentralitas lokal & \\
\hline 2. Outdegree & \\
\hline 3. Maksimum & 8.000 \\
\hline 4. Minimum & 1.000 \\
\hline 5. intdegree & \\
\hline 6. Maksimum & 18.000 \\
\hline 7. Minimum & 0.000 \\
\hline
\end{tabular}

Tabel 1 menjelaskan bahwa Bapak Muhammad Rizal mampu menghubungi 8 orang individu dan di hubungi 18 indvidu lainnya dalam sistem.Posisi individu sebagai ketua mpa dan ketua RT dapat memiliki jaringan komunikasi yang luas atau dapat menjangkau sebagian besar petani dalam jaringan, yang mana indvidu-individu tersebut sering menghubungi bapak Muhammad Rizal untuk berdiskusi terkait dengan metode mengolah lahan tanpa bakar. Hal ini sejalan dengan pendapat Prell (2013) menyatakan bahwa individu yang memiliki derajat outdegree paling tinggi dapat diidentifikasi sebagai pemimpin.

Individu yang memiliki sentralitas lokal rendahminimum adalah Bapak Sugiono, Bapak Sumari, Ibu Salli dan Ibu Sumirem dengan nilai 1.000 dan 0.000 , yang artinya Keempat individu ini dapat dikatakan sebagai Isolatedalam jaringan. Isolate yaitu anggota organisasi yang memiliki kontak/interaksi paling minimum dengan individu lain.

Tabel 2. Nilai maksimum dan minimum sentralitas lokal di Kelurahan Tanjung Palas

\begin{tabular}{lc}
\hline Indeks Jaringan Komunikasi & Kelurahan Tanjung Palas \\
\hline 8. Sentralitas local & \\
9. outdegree & \\
10. Maksimum & 4.000 \\
11. Minimum & 1.000 \\
12. intdegree & \\
13. Maksimum & 14.000 \\
14. Minimum & 0.000 \\
\hline
\end{tabular}

Berdasarkan tabel 2 dapat dilihat bahwa jaringan komunikasi tingkat individu di Kelurahan Tanjung Palas memili nilai outdegree maksimum 4.000 yang ditunjukan oleh bapak Rifai Hasmi artinya beliau dapat menghubungi 4orang individu dalam sistem. Bapak Rifai Hasmi memiliki tingkat popularitas yang tinggi dikarenakan posisinya sebagai ketua lembaga pemberdayaan masyarakat kelurahan (LPMK) Tanjung Palas yang memungkin dapat menghubungi banyak individu dalam jaringan komunikasi.

Nilai indegree maksimum dimiliki oleh Bapak Yustanto dengan nilai 14.000 yang artinya individu ini dihubungi oleh 14 individu lain pada jaringan. Bapak Yustanto merupakan ketua masyarakat peduli api (MPA) Kelurahan Tanjung Palas yang aktif memberikan informasi mengenai membuka atau mengelola lahan tanpa bakar, selain itu beliau juga sering 
berdiskusi kepada masyarakat sehingga cukup dikenal dan dijadikan rujukan untuk mencari informasi mengenai mengelola lahan tanpa bakar.

\section{Sentralitas global}

Nilai sentralitas global menunjukkan jumlah ikatan yang seseorang butuhkan untuk menghubungi semua individu dalam jaringan.

Tabel 3. Nilai sentralitas global di Kelurahan Bangsal Aceh

\begin{tabular}{lc}
\hline Indeks Jaringan Komunikasi & Kelurahan Bangsal Aceh \\
\hline 15. Sentralitas global & \\
16. Maksimum & 702.000 \\
17. Minimum & 34.000 \\
18. Mean & 164,556 \\
\hline
\end{tabular}

Individu yang memiliki nilai sentralitas globalterendah yaitu Bapak Muhammad Rizal, Yang artinya bahwa memiliki kemampuan lebih cepat untuk menghubungi individu lain dalam suatu sistem daripada individu yang nilai sentralitas globalnya tinggi karena mereka lebih lebih sedikit membutuhkan perantara

Tabel 4. Nilai sentralitas global di Kelurahan Tanjung Palas

\begin{tabular}{lc}
\hline Indeks Jaringan Komunikasi & Kelurahan Tanjung Palas \\
\hline 19. Sentralitas global & \\
20. Maksimum & 420.000 \\
21. Minimum & 26.000 \\
22. Mean & 308,333 \\
\hline
\end{tabular}

Nilai sentralitas global minimum dimiliki oleh BapakYustanto yang berperan sebagai ketua MPA artinya bahwa individu ini memerlukan jarak (distance) atau perantara yang lebih sedikit dibanding individu lain untuk dihubungi oleh individu lain pada jaringan.

\section{Kebersamaan}

Menurut Prell (2013) ,tingkat kebersamaan menekankan pada potensi kontrol dalam aliran informasi. Individu dengan nilai kebersamaan tinggi mempunyai potensi kendali komunikasi yang dapat memainkan potensi sebagai broker atau gatekeeper dalam suatu jaringan.

Tabel 5.Nilai kebersamaan di Kelurahan Bangsal Aceh

\begin{tabular}{|c|c|}
\hline Indeks Jaringan Komunikasi & Kelurahan Bangsal Aceh \\
\hline \multicolumn{2}{|l|}{ 23. Sentralitas global } \\
\hline 24. Maksimum & 428.000 \\
\hline 25. Minimum & 0.000 \\
\hline 26. Mean & 38,407 \\
\hline Jaringan $\quad$ komunikasi & $\overline{\text { RT 07), dan Bapak Tugimin (ketua RT }}$ \\
\hline mengelola lahan tanpa bakar di & 08). Individu yang memiliki nilai \\
\hline Kelurahan Bangsal Aceh memiliki nilai & kebersamaan tertinggi yang memungkin \\
\hline kebersamaan maksimum 428.000 & individu tersebut berperan sebagai \\
\hline ditunjukkan oleh Bapak Muhammad & gatekeeper yang memiliki \\
\hline Rizal (ketua MPA), Bapak Admean & komunikasi. \\
\hline
\end{tabular}

(ketua RT 06), Bapak Ali Sugianto

(ketua RT 10), Bapak Jonathan (ketua 
Tabel 6. Nilai kebersamaan di Kelurahan Tanjung Palas

\begin{tabular}{|c|c|}
\hline \multicolumn{2}{|l|}{ Indeks Jaringan Komunikasi } \\
\hline \multicolumn{2}{|l|}{ 27. Sentralitas global } \\
\hline 28. Maksimum & 45.667 \\
\hline 29. Minimum & 0.000 \\
\hline 30. Mean & 6.429 \\
\hline nilai kebersamaan maksimum di & aktor Yustanto dan Warino. Sebaiknya \\
\hline Kelurahan Tanjung Palas yaitu 45.667 & struktur jaringan komunikasi yang \\
\hline yang ditunjukan oleh bapak Yustanto & terbentuk yaitu struktur semua saluran \\
\hline Artinya adalah node Bapak Yustanto & (all Channel) agar setiap individu dalam \\
\hline mempunyai kendali komunikasi dalam & jaringan dapat melakukan interaksi \\
\hline jaringan komunikasi dalam & secara timbal balik tanpa menganut \\
\hline sistemnya.Bapak Yustanto merupakan & siapa yang menjadi tokoh sentral dalam \\
\hline ketua lembaga masyarakat peduli api & memperoleh informasi. Sehingga \\
\hline (MPA). & $\begin{array}{l}\text { informasi terkait dengan metode } \\
\text { memgolah lahan tanpa bakar ini merata }\end{array}$ \\
\hline IV.KESIMPULAN & kesetiap individu. \\
\hline
\end{tabular}

DAFTAR PUSTAKA

dilakukan mengenai jaringan komunikasi mengolah lahan tanpa bakar di Kelurahan Bangsal Aceh dan Kelurahan Tanjung Palas Kota Dumai, Pengolahan lahan yang biasa di lakukan oleh masyarakat di Kota Dumai adalah dengan cara di bakar namun setelah adanya undang-undang No 18 Tahun 2004 terkait larangan mengolah lahan dengan cara bakar, masyarakat diharuskan untuk beralih mulai menerapkan metode mengolahan lahan dengan cara tanpa bakar yang lebih ramah lingkungan guna meminimalisur tingginya tingkat kebakaran lahan di Kota Dumai. Struktur jaringan komunikasi yang terbentuk di Kelurahan Bangsal Aceh dan Kelurahan Tanjung Palas medekati struktur roda, Bentuk jaringan yang memusat pada beberapa indvidu dalam jaringan menjadi ciri utama pada struktur ini. Hal ini dapat dilihat pada di Kelurahan Bangsal Aceh informasi terpusat pada aktor Muhammad Rizal sedangkan di Kelurahan Tanjung palas terpusat pada
Onrizal. 2008. Pembukaan lahan dengan dan tanpa bakar. Universitas Sumatra utara. Medan.
Rahmawati, A. 2016. Analisis Jaringan Komunikasi Dalam Diseminasi Informasi Produksi Dan Pemasaran Jeruk Pamelo (Communication Network Analysis in Dissemination of Pummelo Fruits Production and Marketing Information). Jurnal Komunikasi Pembangunan. 14(01): 1-12

Scott, W.R . 2009. Social Networks Analysis: A Handbook Second Edition. Sage Publications. California.

Prell C. 2013. Social Network Analysis: History, Theory \& Metodology. Singapore: SAGE.

Sulistiawati, A. 2014. Analisis Jaringan Komunikasi dalam Gabungan Kelompok TanIi Berkah. Jurnal Sosiologi Pedesaan. 2(2): 76-82. 